\title{
ANALISA PENDAPATAN SAYURAN PADA KAWASAN RUMAH PANGAN LESTARI (KRPL) KAMPUNG HIJAU DESA KLAMPOKAN
}

\author{
Ari Krisdiantoro'), Sasmita Sari ${ }^{2 *}$ \\ Program Studi Agribisnis, Fakultas Pertanian, Universitas Abdurachman Saleh Situbondo \\ Email Korespondensi : biantaka13@gmail.com
}

\begin{abstract}
Abstrak
Kawasan rumah pangan lestari merupakan suatu program dari pemerintah untuk mewujudkan ketahanan pangan sebagai pondasi pembangunan dari sektor-sektor lainnya. Sasaran program KRPL adalah warga yang mempunyai pekarangan terlantar (tidak dimanfaatkan) untuk dijadikan tempat tanam. Setiap anggota wajib mengembangkan pemanfaatan pekarangan dengan menanam tanaman sumber pangan (sayur, buah, umbi) ataupun memelihara ternak dan ikan. Tujuannya adalah menncukupi ketersediaan pangan dan gizi ditingkat rumah tangga. Hasil dari usaha pekarangan ini diutamakan untuk dikonsumsi oleh rumah tangga bersangkutan dan apabila berlebih dapat dibagikan/disumbangkan kepada anggota kelompok.Setiap pekarangan rumah anggota kelompok diharapkan dilengkapi dengan sarana pembuatan pupuk kompos dari sisa-sisa tanaman dan kotoran ternak dan sisa-sisa limbah dapur untuk digunakan sendiri. Pembangunan ketahanan pangan di indonesia ditunjukkan untuk menjamin ketersediaan dan konsumsi pangan yang cukup, aman, bermutu bergizi dan seimbang pada tingkat rumah tangga, daerah, nasional, sepanjang waktu dan merata. Hal ini dapat di lakukan melalui pemanfaatan sumber daya dan budaya lokal, teknologi inovatif dan peluang pasar. Salah satu contohnya yaitu melalui penanam sayuran di pekarangan rumah, dengan tujuan memenuhi kebutuhan konsumsi setiap harinya. Kawasan Rumah Pangan Lestari (KRPL) Kampung Hijau inilah peneliti akan menganalisa bagaimana pendapatan pada KRPL tersebut, apakah menguntungkan atau tidak dalam produksinya. Tujuan penelitian ini adalah untuk mengetahui pendapatan pada Kawasan Rumah Pangan Lestari (KRPL) Kampung Hijau Desa Klampokan Kecamatan Panji Kabupaten Situbondo apakah menguntungkan atau tidak untuk diusahakan. Sampel dalam penelitian ini adalah anggota Kawasan Rumah Pangan Lestari (KRPL) Kampung Hijau yang menanam sayuran yaitu berjumlah 15 orang. Analisis yang digunakan dalam penelitian ini adalah analisis pendapatan dan R/C Ratio.
\end{abstract}

Kata kunci : Pendapatan, Sayuran, KRPL

\begin{abstract}
The sustainable food house area is a program of the government to realize food security as a foundation for the development of other sectors. The target of the KRPL program is for residents who have abandoned yards (not used) to be planted. Each member must develop the use of the yard by planting food sources (vegetables, fruits, tubers) or raising livestock and fish. The aim is to meet the availability of food and nutrition at the household level. The results of this plot are prioritized for consumption by the household concerned and if excess can be distributed / donated to group members. Each group member's house is expected to be equipped with a means of making compost from plant remains and livestock droppings and remnants of kitchen waste for used alone. The development of food security in Indonesia is shown to ensure the availability and consumption of sufficient, safe, nutritious and balanced food at the household, regional, national level, at all times and evenly. This can be done through the use of local culture and resources, innovative technology and market opportunities. One example is through vegetable growers in home yards, with the aim of
\end{abstract}


meeting daily consumption needs. The Kampung Hijau Sustainable Food House (KRPL) area, the researcher will analyze how the income in the KRPL, whether profitable or not in its production. The purpose of this study was to determine the income in the Sustainable Food Houses (KRPL) Kampung Hijau Village, Klampokan Village, Panji Subdistrict, Situbondo Regency, whether it was profitable or not. The sample in this study were members of the Green Village Sustainable Food Houses (KRPL) who planted vegetables amounting to 15 people. The analysis used in this study is the analysis of income and R / C Ratio.

Keywords: Income Vegetable, dan KRPL.

\section{PENDAHULUAN}

Kawasan Rumah Pangan Lestari diwujudkan dalam satu Rukun Tetangga atau Rukun Warga/Dusun (Kampung) yang telah menerapkan prinsip Rumah Pangan Lestari dengan menambahkan intensifikasi pemanfaatan pagar hidup, jalan desa, dan fasilitas umum lainnya (Sekolah, rumah ibadah dan lainnya), lahan terbuka hijau, serta mengembangkan pengolahan dan pemasaran hasil. Kementrian Pertanian telah menyusun konsep Model Kawasan Rumah Pangan Lestari yang merupakan himpunan dari Rumah Pangan Lestari (RPL) yaitu rumah tangga dengan prinsip pemanfaatan pekarangan yang ramah lingkungan dan dirancang untuk pemenuhan kebutuhan pangan dan gizi keluarga, diversifikasi pangan berbasis sumberdaya lokal, pelestarian tanaman pangan untuk masa depan serta peningkatan pendapatan yang pada akhirnya akan meningkatkan kesejahteraan masyarakat. Untuk menjaga keberlanjutannya, pemanfaatan pekarangan dalam konsep model KRPL dilengkapi dengan kelembagaan kebun bibit Desa, Unit pengolahan serta pemasaran untuk penyelamatan hasil yang melimpah (Kementrian Pertanian, 2011).

Pangan adalah kebutuhan dasar manusia yang pemenuhannya dijamin oleh Undang-Undang Nomor 18 Tahun 2012 tentang Pangan. Tidak hanya sekedar memenuhi kuantitas pangan tetapi juga kualitasnya. Pasal 60 UU No 18/2012 mengamanatkan bahwa Pemerintah dan Pemerintah Daerah berkewajiban mewujudkan penganekaragaman konsumsi pangan untuk memenuhi kebutuhan gizi masyarakat sesuai dengan potensi dan kearifan lokal guna mewujudkan hidup sehat, aktif, dan produktif. Penjabaran dari Undang-Undang Pangan tersebut telah diterbitkan Peraturan Pemerintah Nomor 17 Tahun 2015 tentang Ketahanan Pangan dan Gizi dimana dalam Pasal 26 disebutkan bahwa upaya penganekaragaman pangan salah satunya dilakukan melalui pemanfaatan lahan pekarangan (Kementrian Pertanian RI, 2018).

Tabel 1. Data Desa Yang Menerima Bantuan Program Kawasan Rumah Pangan Lestari (KRPL) Di kabupaten Situbondo Tahun 2018

\begin{tabular}{clll}
\hline No & \multicolumn{1}{c}{ Desa } & \multicolumn{1}{c}{ Kecamatan } & \multicolumn{1}{c}{ KRPL } \\
\hline 1 & Sumber Kolak & Panarukan & Patas Asri \\
2 & Talkandang & Situbondo & Dahlia \\
3 & Klampokan & Panji & Kampung Hijau \\
4 & Kapongan & Kapongan & Kapongan Bersinar \\
5 & Gunung Putri & Suboh & Gunung Putri \\
\hline
\end{tabular}

Sumber : Dinas Ketahanan Pangan Dan hortikultura Kabupaten Situbondo Tahun 2018

Terkait dengan adanya KRPL tersebut, peran serta masyarakat dan pemerintah dalam kegiatan Kawasan Rumah Pangan Lestari yang bertempat di Desa Klampokan, Kecamatan Panji, Kabupaten Situbondo diharapkan akan mensejahterahkan masyarakat disekitar terutama keluarga sendiri. Walaupun dalam kegiatan tersebut masih terdapat beberapa kendala akan tetapi dapat dilanjutkan secara terus menerus. Berdasarkan 
penjelasan di atas, maka peneliti tertarik untuk melakukan penelitian berjudul "Analisa Pendapatan Kawasan Rumah Pangan Lestari (KRPL) Kampung Hijau Di Desa Klampokan".

Dari penjelasan diatas dapat ditarik rumusan masalah Berapa pendapatan usaha sayuran pada Kawasan Rumah Pangan Lestari (KRPL) Kampung Hijau di Desa Klampokan dan dari usaha tersebut apakah Kawasan Rumah Pangan Lestari (KRPL) Kampung Hijau efisien untuk diusahakan.

\section{METODE PENELITIAN Populasi dan Sampel}

Pengertian populasi menurut Sugiono (2013) adalah Penelitian kuantitatif populasi diartikan sebagai wilayah generalisasi yang terdiri atas: obyek/subyek yang mempunyai kualitas dan karakteristik tertentu yang di tetapkan oleh peneliti untuk dipelajari dan kemudian di tarik kesimpulannya. Populasi dalam penelitian ini adalah semua anggota Kawasan Rumah Pangan Lestari (KRPL) Kampung Hijau Desa Klampokan yang berjumlah 30 orang anggota.

Sedangkan sampel adalah bagian atau jumlah dan karakteristik yang dimiliki oleh populasi tersebut. Bila populasi besar dan peneliti tidak mungkin mempelajari semua yang ada pada populasi, missal karna keterbatasan dana, tenaga dan waktu, maka peneliti akan mengambil sampel dari populasi itu. Kesimpulannya akan diberlakukan untuk populasi. Untuk itu sampel yang diambil dari populasi harus betul-betul respresentative (Sugiono, 2015). Populasi dalam penelitian ini adalah semua anggota KRPL Kampung Hijau Desa Klampokan yang beranggotakan 30 orang dimana anggota tersebut akan diambil 15 orang untuk dijadikan sampel, karena pada peneliti hanya fokus pada anggota yang menanam sayuran yaitu berjumlah 15 orang, sedangkan yang 7 orang beternak ayam dan 8 orang memelihara ikan.

\section{Tehnik Analisis Data}

Analisis data yang digunakan dalam penelitian Kawasan Rumah Pangan Lestari (KRPL) yaitu untuk mengetahui biaya yang dikeluarkan dalam setiap kegiatan yang dijalankan dan juga untuk mengetahui pendapatan yang didapat dari setiap hasil yang didapatkan atau jumlah produksi dari kegiatan KRPL di Desa Klampokan. Oleh karena itu untuk mengetahui berapa biaya yang dikeluarkan dan berapa pendapatan yang di hasilkan dari KRPL di Desa Klampokan digunakanlah rumus sebagai berikut :

1). Menghitung usaha KRPL.

Biaya yang dimaksud dalam penelitian ini adalah biaya yang benar-benar dikeluarkan oleh KRPL yang meliputi biaya tenaga kerja, pembelian pupuk, benih, pestisida, dan sarana produksi lainnya serta biaya irigasi.

2). Menghitung penerimaan usaha KRPL

$$
\mathrm{TR}=\mathrm{P} \text { X Q }
$$

Keterangan :

$\mathrm{TR}=$ Total Reveneu/Penerimaan yang diperoleh KRPL

$\mathrm{P} \quad=$ Harga produksi dari KRPL

$\mathrm{Q} \quad=$ Hasil produksi KRPL

3). Menghitung pendapatan usaha KRPL.

$$
\Pi=\mathrm{TR}-\mathrm{TC}
$$

Keterangan :

$\Pi \quad=$ Total Income/Pendapatan Yang diperoleh KRPL

$\mathrm{TR}=$ Total Reveneu/Penerimaan Yang Diperoleh KRPL

$\mathrm{TC}=$ Total Cost/biaya Yang Dikeluarkan KRPL 
Metode yang digunakan untuk mengetahui tingkat efisien usaha di KRPL Kampung Hijau Desa Klampokan di gunakan rumus :

Dari rumus diatas dapat diketahui kriteria dari R/C Ratio sebagai berikut :

$$
\mathrm{R} / \text { Crasio }=\frac{\text { Penerimaan }(R)}{\operatorname{Biaya}(C)}
$$

Apabila R/C Ratio > 1 maka usaha KRPL dikatakan efisien.

Apabila R/C Ratio < 1 maka usaha KRPL dikatakan tidak efisien.

Apabila R/C Ratio = 1 maka usah KRPL dikatakan impas.

\section{HASIL DAN PEMBAHASAN}

\section{Analisis Pendapatan Kawasan Rumah Pangan Lestari (KRPL) Kampung Hijau Desa Klampokan \\ Biaya Produksi}

Biaya produksi merupakan biaya keseluruhan yang dikeluarkan dalam usaha tani untuk menghasilkan suatu produk pertanian. Besarnya biaya produksi yang dikeluarkan akan mempengaruhi penerimaan pendapatan akhir dari petani, biaya produksi yang dipergunakan yaitu biaya tetap dan biaya variabel. Dimana biaya tetap merupakan biaya yang penggunaannya tidak habis dalam satu kali masa produksi dalam hal ini yang termasuk dalam biaya tetap pada Kawasan Rumah Pangan Lestari (KRPL) Kampung Hijau yaitu cangkul, sekop, dan arit.

Tabel 2. Biaya Produksi Kawasan Rumah Pangan Lestari (KRPL) Kampung Hijau

\begin{tabular}{clrr}
\hline No & \multicolumn{1}{c}{ Jenis Biaya } & Jumlah (Rp) & \multicolumn{1}{c}{ Rata-rata } \\
\hline 1 & Biaya Tetap & 1785000 & 119000 \\
2 & Biaya Variabel & 1076000 & 71733,33 \\
3 & Biaya Tenaga Kerja & 745000 & 49666,66 \\
\hline Total Biaya & & 3606000 & 240400 \\
\hline
\end{tabular}

Sumber : Hasil Olahan Data Primer tahun 2019

Dari tabel diatas, dapat diketahui bahwa biaya produksi yang dikeluarkan pada Kawasan Rumah Pangan Lestari (KRPL) Kampung Hijau Desa Klampokan sebesar Rp.3.606.000 dengan rata-rata sebesar Rp.240,400. Diperoleh dari hasil biaya tetap (Tf) ditambah biaya variabel $(\mathrm{Fc})$ dan ditambah biaya tenaga kerja (Tk).

Dari total biaya keseluruhan dapat dirinci yaitu biaya tetap sebesar Rp.1.785.000 dengan rincian yaitu berupa cangkul sebesar Rp.595.000, sekop sebesar Rp680.000, dan arit sebesar Rp.510.000. Sedangkan biaya variabel sebesar Rp.1.076.000 dengan rincian berupa polibag sebesar Rp.72.000 benih selada sebesar Rp.45.000, sawi sebesar Rp.120.000, brokoli sebesar Rp.200.000, seladri sebesar Rp.200.000, dan kangkung sebesar Rp.220.000, biaya tenaga kerja sebesar Rp.745.000, pupuk berupa pupuk NPK sebesar Rp.60.000, pupuk Urea sebesar Rp.95.000, dan biaya obat sebesar Rp.64.000. Sedangkan biaya tenaga kerja sebesar Rp.745.000 dengan rata-rata sebesar Rp.49666,67 dengan rincian yaitu pengolahan lahan sebesar Rp.400.000, pemupukan sebesar Rp.750.000, penyemprotan sebesar Rp.105.000, penyiangan sebesar Rp.85.000, dan pemanenan sebesar Rp.80.000.

Maka dapat diketahui biaya produksi yang dikeluarkkan setiap panen pada Kawasan Rumah Pangan Lestari (KRPL) Kampung Hijau Desa Klampokan Rata-rata sebesar Rp.240.400/panen. 


\section{Penerimaan Kawasan Rumah Pangan Lestari (KRPL) Kampung Hijau}

Untuk mengetahui penerimaan Kawasan Rumah Pangan Lestari (KRPL) Kampung Hijau Desa Klampokan dapat diperoleh melalui analisis penerimaan dengan rumus :

$$
\mathrm{TR}=\mathrm{P} X \mathrm{Q}
$$

Keterangan :

$\mathrm{TR}=$ Total Reveneu/Penerimaan yang diperoleh KRPL

$\mathrm{P} \quad=$ Harga produksi dari KRPL

$\mathrm{Q}=$ Hasil produksi KRPL

Penerimaan adalah perkalian antara hasil produksi dengan harga produksi. Penerimaan disini merupakan hasil produksi sayuran (selada, sawi, brokoli, seladri, dan kangkung) dikali dengan harga produksi sayuran (selada, sawi, brokoli, seladri, dan kangkung) pada Kawasan Rumah Pangan Lestari (KRPL) Kampung Hijau Desa Klampokan. Berikut adalah tabel penerimaan Kawasan Rumah Pangan Lestari (KRPL) Kampung Hijau Desa Klampokan :

Tabel 3. Produksi, Harga, dan Penerimaan Kawasan Rumah Pangan Lestari (KRPL) Kampung Hijau

\begin{tabular}{clccc}
\hline No & Jenis Sayur $(\mathrm{kg})$ & Produksi $(\mathrm{kg})$ & Harga $(\mathrm{Rp})$ & Penerimaan $(\mathrm{Rp})$ \\
\hline 1 & Selada & 84 & 25.000 & 2.100 .000 \\
2 & Sawi & 85 & 13.000 & 1.105 .000 \\
3 & Brokoli & 71 & 20.000 & 1.420 .000 \\
4 & Seledri & 13 & 20.000 & 251.000 \\
5 & Kangkung & 91 & 10.000 & 910.000 \\
\hline & Jumlah & & 5.786 .000 \\
\hline & Rata-Rata & & 385733.33 \\
\hline
\end{tabular}

Sumber : Hasil Olahan Data Primer tahun 2019

Dari tabel diatas dapat dijelaskan bahwa penerimaan setiap panen sebesar Rp.5.786.000 dengan jumlah rata-rata sebesar Rp.385.733. Penerimaan tersebut diperoleh melalui jumlah produksi dikali dengan harga produksi.

Dari penerimaan KRPL Kampung Hijau dapat dirinci yaitu produksi selada sebanyak $84 \mathrm{~kg} /$ panen denggan harga Rp. $25.000 / \mathrm{kg}$ dengan jumlah total penerimaan sebesar Rp.2.100.000, produksi sawi sebanyak 85kg/panen dengan harga Rp.13.000/kg dengan jumlah total penerimaan sebesar Rp.1.105.000, produksi brokoli sebanyak $71 \mathrm{~kg} /$ panen dengan harga Rp.20.000/kg degan jumlah total penerimaan sebesar Rp.1.142.000, produksi seladri sebanyak $13 \mathrm{~kg} /$ panen dengan harga Rp.20.000/kg dengan jumlah total penerimaan sebesar Rp.251.000, dan produksi kangkung sebannyak $91 \mathrm{~kg} /$ panen dengan harga Rp.10.000/kg dengan jumlah total penerimaan sebesar Rp.910.000.

Maka dapat diketahui penerimaan Kawasan Rumah Pangan Lestari Kampung Hijau (KRPL) Kampung Hijau Desa Klampokan rata-rata sebesar Rp.385.733/panen.

\section{Pendapatan Kawasan Rumah Pangan Lestari (KRPL) Kampung Hijau}

Untuk mengetahui pendapatan pada Kawasan Rumah Pangan Lestari (KRPL) Kampung Hijau menguntungkan atau tidak maka diperoleh melalui analisis pendapatan dengan rumus :

$$
\Pi=\mathrm{TR}-\mathrm{TC}
$$


Keterangan :

$\Pi \quad=$ Total Income/Pendapatan Yang diperoleh KRPL

TR = Total Reveneu/Penerimaan Yang Diperoleh KRPL

TC = Total Cost/biaya Yang Dikeluarkan KRPL

Pendapatan pada KRPL adalah selisih antara penerimaan dan semua biaya. Penerimaan disini adalah jumlah produksi sayuran (selada, sawi, brokoli, seladri, dan kangkung) dikali harga jual pada sayuran (selada, sawi, brokoli, seladri, dan kangkung), sedangkan biaya adalah semua biaya yang dikeluarkan dalam proses budidaya sayuran (selada, sawi, brokoli, seladri, dan kangkung).

Berikut adalah tabel pendapatan pada Kawasan Rumah Pangan Lestari (KRPL) Kampung Hijau Desa Klampokan :

Tabel 4. Pendapatan Kawasan Rumah Pangan Lestari (KRPL) Kampung Hijau

\begin{tabular}{rlc}
\hline No & Uraian & Jumlah (Rp) \\
\hline 1 & Penerimaan & 5.786 .000 \\
2 & Total Biaya & 3.606 .000 \\
3 & Pendapatan & 2.180 .000 \\
\hline Total & & 2.180 .000 \\
\hline Rata-rata & & 140533,33 \\
\hline
\end{tabular}

Sumber : Hasil Olahan Data Primer tahun 2019

Tabel diatas dapat dijelaskan bahwa pendapatan kawasan Rumah Pangan Lestari (KRPL) Kampung Hijau Desa Klampokan sebesar Rp.2.180.000/panen dengan jumlah rata-rata sebesar Rp.145.333,33 Pendapatan diperoleh melalui penerimaan dikurangi total biaya.

Dari jumlah total pendapatan KRPL Kampung Hijau dapat dirinci yaitu penerimaan sebesar Rp.5.786.000/panen, dan total biaya sebesar Rp.3.606.000/panen.

Maka dapat diketahui pendapatan Kawasan Rumah Pangan Lestari (KRPL) Kampung Hijau rata-rata sebesar Rp.145.333,33/panen.

\section{Analisis Efisiensi Kawasan Rumah Pangan Lestari (KRPL) Kampung Hijau}

untuk mengetahui efisiensi Kawasan Rumah Pangan Lestari (KRPL) Kampung Hijau Desa Klampokan maka diperoleh melelui analisis R/C Ratio dengan Rumus :

$$
\mathrm{R} / \mathrm{C} \text { Rasio }=\frac{\text { Penerimaan }(R)}{\operatorname{Biaya}(C)}
$$

Keterangan : $\mathrm{R}=$ Penerimaan yang diperoleh KRPL

$\mathrm{C}=$ Biaya yang dikeluarkan KRPL

Dari rumus diatas dapat diketahui kriteria dari R/C Ratio sebagai berikut :

Apabila R/C Ratio > 1 maka usaha KRPL dikatakan efisien.

Apabila R/C Ratio < 1 maka usaha KRPL dikatakan tidak efisien.

Apabila R/C Ratio = 1 maka usah KRPL dikatakan impas.

Analisa R/C Ratio Kawasan Rumah Pangan Lestari (KRPL) Kampung Hijau Desa Klampokan adalah analisis untuk mencari efisiensi KRPL Kampung Hijau apakah usaha tersebut efisien atau tidak.

Berikut adalah tabel R/C Ratio Kawasan Rumah Pangan Lestari (KRPL) Kampung Hijau Desa Klampokan : 
Tabel 5. R/C Ratio Kawasan Rumah Pangan Lestari (KRPL) Kampung Hijau

\begin{tabular}{lllc}
\hline \multicolumn{1}{c}{ No } & & \multicolumn{1}{c}{ Uraian } & Jumlah (Rp) \\
\hline & 1 & Penerimaan & 5.786 .000 \\
& 2 & Total Biaya & 3.606 .000 \\
& 3 & R/C Ratio & 1,60 \\
\hline Total & & & 1,60 \\
Rata-rata & & 1,59 \\
\hline
\end{tabular}

Sumber : Hasil Olahan Data Primer tahun 2019

Dari tabel diatas dapat dijelaskan bahwa R/C Ratio Kawasan Rumah Pangan Lestari (KRPL) Kampung Hijau desa Klampokan sebesar 1,60 dengan jumlah rata-rata sebesar 1,59. R/C Ratio diperoleh melalui jumlah penerimaan dibagi total biaya. Dari total R/C Ratio dapat dirinci yaitu penerimaan sebesar Rp.5.786.000 dan jumlah total biaya sebesar Rp.3.606.000. Maka R/C Ratio pada Kawasan Rumah Pangan Lestari (KRPL) Kampung Hijau Desa Klampokan rata-rata sebesar 1,59.

Dengan demikian dapat disimpulkan bahwa R/C Ratio Kawasan Rumah Pangan Lestari (KRPL) Kampung Hijau Desa Klampokan total berjumlah 1,57, artinya satu rupiah yang dikeluarkan dapat menghasilkan 1,57 rupiah. Sehingga apabila R/C Ratio lebih Besar Dari 1 maka usaha Kawasan Rumah Pangan Lestari (KRPL) Kampung Hijau desa Klampokan bisa dikatakan efisien/menguntungkan karena penerimaan yang diterima lebih besar dari pada biaya yang dikeluarkan Kawasan Rumah Pangan Lestari (KRPL) Kampung Hijau.

\section{KESIMPULAN}

Berdasarkan hasil penelitian Analisa Pendapatan Kawasan Rumah Pangan Lestari (KRPL) Kampunng Hijau di Desa Klampokan Kecamatan Panji Kabupaten Situbondo dapat ditarik kesimpulan sebagai berikut :

1. Pendapatan Kawasan Rumah Pangan Lestari (KRPL) Kamppung Hijau Desa Klampokan Kecamatan Panji Kabupaten Situbondo menguntungkan, dimana pendapatan Kawasan Rumah Pangan Lestari (KRPL) Kampung Hijau rata-rata sebesar Rp140.533,33/panen.

2. Usaha pada Kawasan Rumah Pangan Lestari (KRPL) Kampung Hijau di Desa Klampokan efisien berdasarkan pada analisis R/C Ratio, dimana tingkat efisien ratarata sebesar 1,59. Artinya 1 Rupiah biaya yang dikeluarkan menghasilkan 1,56 Rupiah yang didapat.

\section{REFERENSI}

Desti Rahayu Ardia. (2015) "Analisa Kelayakan Usaha Gula semut Anggota Koperasi Serba Usaha (KSU) Jatirogo”. Skripsi Universitas Negri Yogyakarta, Fakultas Ekonomi

Dinas Pemberdayaan Masyarakat Desa. (2019) "Format Isian Data Profil Tahun 2019". Situbondo. Desa Klampokan.

Ferdian, Miemin heni Irawati Al-muhdhar Dan Suhadi. (2016). "Pengembangan Booklet Program Kawasan Rumah Pangan Lestari Dan Pengaruhnya Terhadap Pengetahuan Lingkungan Masyarakat Di Kota Malang". Jurnal Pendidikan. Universitas Malang.

Kementrian Pertanian RI. (2018). "Petunjuk Teknis Optimalisasi Pemanfaatan Lahan Pekarangan Melalui Kawasan Rumah Pangan Lestari (KRPL) Tahun 2018". 
Ni Luh Putu Chandra Dewi, Wayan sudarta Dan I Gede Setiawan Adi Putra. (2015). "Partisipasi Anggota Kelompok Tani Pangan Sari Pada Program Kawasan Rumah Pangan Lesatari (Study Kasus Di Desa Cengkilung, Desa Peguyangan Kangin, Kecamatan Denpasar Utara, Kabupaten Denpasar). E-Jurnal Agrbisnis Dan Agrowisata. Universitas Udayana. 